\title{
FACTORS ENDANGERING THE PROFESSIONAL ACTIVITY OF THE EMERGENCY MEDICAL PROFESSIONALS
}

\author{
D. Todorova*, A Andonova \\ Faculty of Medicine, Trakia University, Stara Zagora, Bulgaria
}

\begin{abstract}
The endangering factors from the professional activity of the medical teams working at CEMC to be more comprehensively studied, analyzed and summarized. Preliminary interviews were conducted with medical professionals working at CEMC. On this basis, a questionnaire was developed, surveying through a sociological method the opinion of medical professionals from the Centers for Emergency Medical Care. The implemented structural and organizational changes still do not outline fully clear perspectives ahead of the work of the emergency rooms. These ambiguities suppose the risky nature (endangering factors) of the activity of the emergency medical professionals. In the outlining of the factors endangering the professional activity of the emergency medical professionals who work at the emergency centers the questions of interest are related to: the difficulties that they face during the execution of their professional obligations, the most exhausting components of the work, the workplace aggression and so on. Factors endangering the professional activity of the emergency medics determine their choice of job which on the other hand is a really important factor that determines job satisfaction.
\end{abstract}

Key words: Center for Emergency Medical Care, sustainability, policy, challenges.

\section{INTRODUCTION}

The demographic, social and household and economic processes during the last decades have a number of negative trends in public relations. The change of the structure, organization and health financing determined many positive and negative attitudes and relationships between patients and medical professionals. One of the most affected by the negative changes is the emergency medicine sector. Factors endangering the professional activity of the medical professionals that work in emergency care are numerous, variable, and directly affecting the professional activities and characteristics of the medical profession.

The work of the emergency medical professionals is one of the most responsible but also associated with the greatest workload.

Different factors endanger the professional activity of emergency medics - fatigue,

\footnotetext{
*Correspondence to: DEYANA GENCHEVA TODOROVA, Faculty of Medicine, Trakia University, Stara Zagora Armeyska Str. 11; Bulgaria; mob. tel.: +359 8880095 40; e-mail: deyanatodorova@abv.bg
}

performing non-medical activities and such that require higher professional qualification, psycho-emotional stress, fake calls, bad information system, various forms of violence and harassment, low wages, shortage of staff and others.

The impact of these factors on the professional activity of the emergency medics influences their adaptation to the changing social and economic environment as it hinders the sustainability of their own homeostasis and basic structurally functional characteristics of their personality at the same time.

The results from the survey about the factors endangering the professional activity of the emergency medical professionals predetermine the undertaking of events to increase the satisfaction and the efficiency of their activity $[4,8]$.

\section{MATERIALS AND METHODS}

The following materials and methods were used for the solution of the set tasks:

1. Analysis of documents 
Available literature sources, official published normative acts related to the legal regulation of emergency medical care until 2020 are analyzed.

Annual reports on the activity of the Center for Emergency Medical Aid (CSMP) and the Branch for Emergency Medical Aid (FSMP) in the country are also analyzed.

2. Analysis of media materials - print media, internet, television, radio, etc.

The realization of the tasks, the summary and the analysis of the obtained results was carried out by applying the following methods: historical, monographic, analysis and synthesis, method of comparison, induction and deduction, method of expert evaluation and empirical sociological research.

3. Sociological methods

A survey was conducted through interviews and three direct anonymous surveys related to the structure and organization of work, motivation for work, problems of emergency medical professionals, the introduction of telemedicine and patients in 2019 and 2020 with 325, 50 medical professionals and 200 patients. A personal expert assessment was made by the heads of CSMP and FSMP.

The study was conducted in CSMP and FSMP from different regions of the country with different structure and organization of work, which will allow us to analyze the work and problems of medical professionals providing emergency care in general.

4. Statistical methods

4.1. Descriptive statistics

One-dimensional frequency tables for category variables by calculating:

- absolute frequency - number of valid answers for each category of the variable;

- relative frequency - a percentage of valid answers for each category of the variable from the total number;

- percentage of valid answers - a percentage of valid answers for each category of the variable from the number of valid answers;

- cumulative percentage - a cumulative percentage of all categories of the variable.

4.2. Two-dimensional frequency tables for the category variables (Cross tables $2 \times 2$ and nxn depending on the categories of the variables) with a calculation of number and percentage of the total number.

5. Graphic analysis:

- pie and bar charts of the distribution for the category variables.

6. Statistical methods for dependencies:
TODOROVA D., et al.

6.1. Test of statistical hypotheses for dependencies between two category variables: - coefficient $\chi^{2}$ (Pearson's method) - used for $2 \times 2$ Cross Table, when the expected frequencies in each cell of the table is $>5$;

- Fisher's exact method - used in 2x2 Cross Table, when the expected frequencies in some cells of the table is $<5$;

- linear coefficient $\chi^{2}$ - used at nxn Crosstable, when the expected frequencies in each cell of the table are $>5$;

- coefficient $\chi^{2}$ (Kruskal-Wallis method) - used for nxn Cross-table, when the expected frequencies in some cells of the table are $<5$.

6.2. A statistically significant result is considered to be the significance level of the null hypothesis $\mathrm{p}<0.05$.

Statistical processing of empirical data was performed using a package for statistical analysis - statistical program SPSS 20 designed for research in the social sciences and Microsoft Office Excel 2016.

\section{RESULTS AND DISCUSSION}

There is a categorical manifestation of the impact of the factor performing activities that require higher professional qualification in the process of performing professional duties as highly endangering. In other words, $72.8 \%$ of the medical professionals examined indicated that. Only $11.1 \%$ indicated that they do not perform such activities, $15.3 \%$ could not judge. Some of them indicated - all the time because the team is engaged during the greater part of the duty while in the branch there is no other medical person but the nurse who does not have competence in every medical specialty. These results are shown in Figure 1.

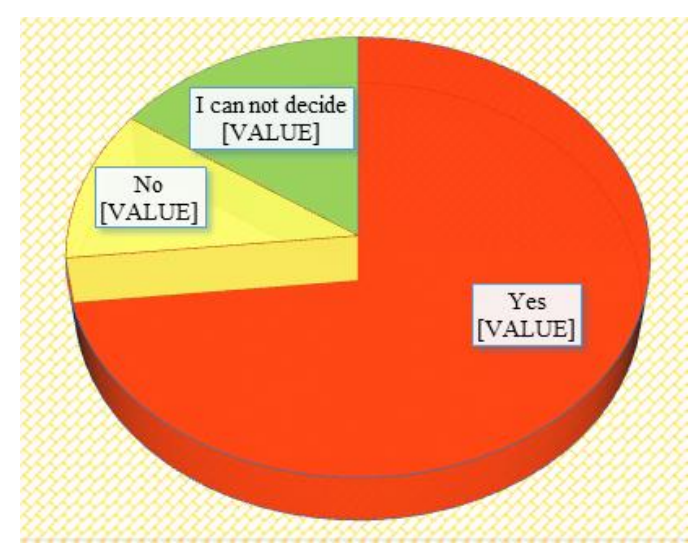

Figure 1. Performing activities requiring higher professional qualification

From the data set out in Figure 2 and its analysis of the degree of risk of professional 
activity of the factor - performing non-medical activities at work shows that $79.6 \%$ of the whole totality of the emergency medics confirms they perform non-medical activities (sanitary, social activities, etc.) at work and respectively they assess that as a highly influential endangering factor. According to them the EMS performs uncharacteristic activities as it plays the role of a buffer between the prehospital and the hospital services.

$12.8 \%$ of the respondents indicated they do not perform non-medical activities at work and such activities do not accompany their professional activity. $6.8 \%$ could not judge.

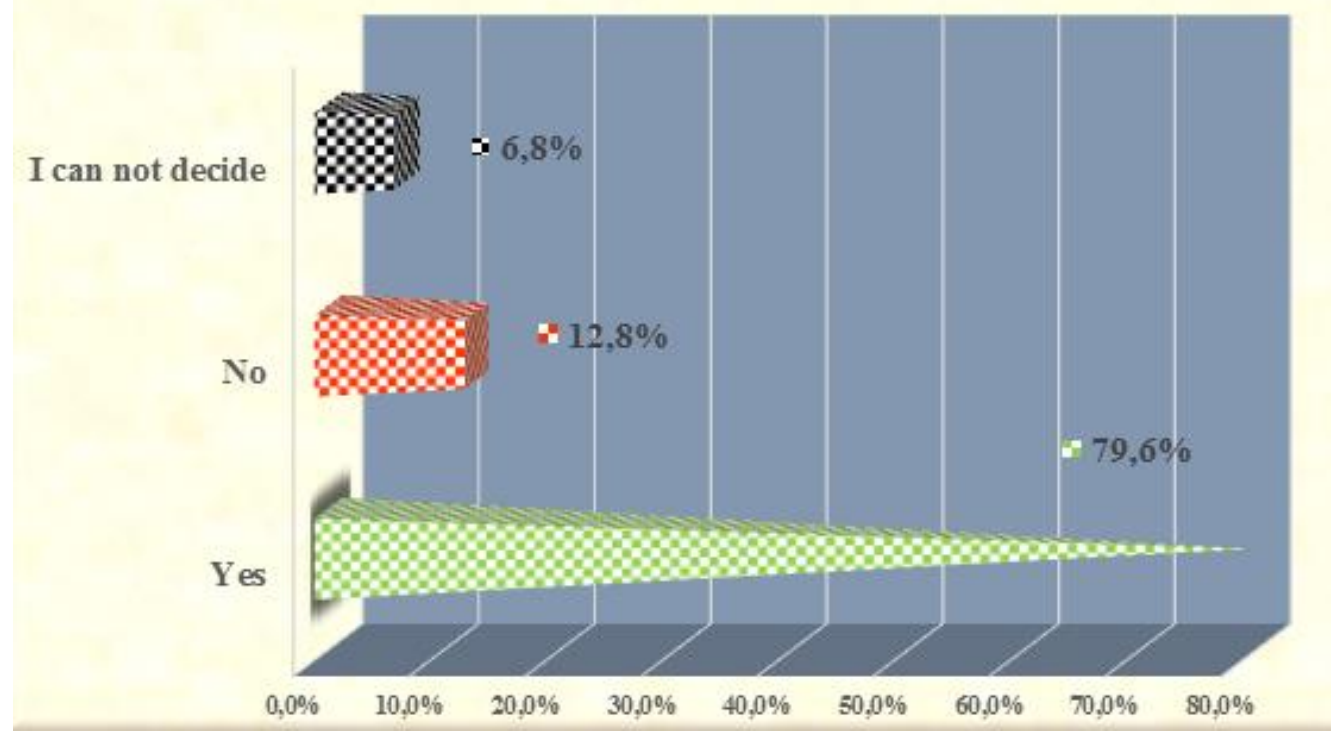

Figure 2. Performing non-medical activities at work

The study made determines the following conclusions:

1. As one of the main factors endangering the professional activity emerge - performing activities that require higher professional qualification and non-medical activity during work.

2. The medical professionals that provide emergency medical care are facing many factors endangering their professional activity that require a prompt and adequate answer.

3. Options should be sought to overcome the difficulties that the emergency workers face daily, and work should be done a lot in the direction of real interaction between all subjects.

\section{CONCLUSION}

The study made allows the following conclusion to be made:

Factors endangering the professional activity of the emergency medics determine their choice of job which on the other hand are a really important factor that determines job satisfaction.

\section{REFERENCES}

1. Katelieva D. and Georgieva L., Medical triage in emergency care - development and application. Emergency Medicine, 20(1):7276, 2016.

2. Katelieva D. and Georgieva L., Possibilities for optimization of outpatient emergency medical care to achieve early access to patients. Health Policy and Management, 3: 7-10; 2015.

3. Mircheva S., M. Milanova G. Todorova and D. Rangelova I. The shortage of health care specialists - a looming problem for the nation's health care. Emergency Medicine, 21(1):91-94, 2017.

4. Ministry of Health, Regulations for amendment and supplement of the Regulations for the structure and activity of an emergency medical care center (promulgated, SG No. 98/1999; amended and supplemented, SG No. 7/2007)., issue 9 of 2009 and issue 13 of 2011).

5. Project BG05M9OP001-3.007-0001 "Improvement of the conditions for treatment of emergencies", funded by the European Social Fund through the Operational Program "Human Resources Development" 2014-2020.

6. Weibel L, Gabrion I, Aussedat M, Kreutz G., Work-related stress in an emergency medical dispatch center. Annals of 
TODOROVA D., et al.

Emergency Medicine, 41 (4):500-506, 2003.

7. Peter Drew, Vivienne Tippett, and Scott Devenish. "Effectiveness of mitigation interventions on occupational violence against emergency service workers," JBI Database of Systematic Reviews and Implementation Reports, 16(5):1081-1086, 2018.
8. Concept for development of the system for emergency medical care in the Republic of $\begin{array}{llll}\text { Bulgaria } 2014 \quad- & 2020\end{array}$ (https://www.mh.government.bg/media/file r_public/2015/04/15/kontseptsiya-razvitiena-speshnata-meditsinska-pomosht_26-112014.pdf ). 